\title{
Bacteriological Profile of Organisms Isolated from Patients with Conjunctivitis in Katihar, Bihar
}

\author{
Priya Sinha1, Sangeeta Dey², Aninda Sen³, Kahkashan Akhter ${ }^{4}$, Alok Kumar ${ }^{5}$, Shreshy Singh ${ }^{6}$ \\ 1, 2, 3, 4, 6 Department of Microbiology, Katihar Medical College, Katihar, Bihar, India. \\ ${ }^{5}$ Department of Microbiology, Sanjeevni Netralaya, Katihar, Bihar, India.
}

\section{ABSTRACT}

\section{BACKGROUND}

Conjunctivitis is one of the most common nontraumatic eye complaints and is one of the most frequently reported diseases in the outpatient and emergency departments. Bacterial conjunctivitis has been reported as one of the most common type of infectious conjunctivitis after viral infections. It is also considered as the primary cause of acute conjunctivitis in children. This study was conducted to isolate and identify organisms causing bacterial conjunctivitis and to determine their in vitro susceptibility or resistance.

\section{METHODS}

This descriptive study was conducted in the Departments of Ophthalmology and Microbiology at Katihar Medical College from December 2018 to May 2020. Sociodemographic and clinical data were collected from 175 patients using structured questionnaire. External ocular specimens were collected using sterile swabs and inoculated on blood agar, MacConkey's agar and chocolate agar. Presumptive isolates were further identified by a series of biochemical tests. All isolated organisms were tested for their in vitro antimicrobial susceptibility against various antibiotics using the Kirby-Baur disk diffusion method.

\section{RESULTS}

A total of 175 samples were collected, out of which, $62.8 \%$ (110 / 175) showed growth of bacteria. Maximum cases of bacterial conjunctivitis were seen in the age group 11 - 20 years. The male to female ratio was 2.7:1. Maximum frequency of bacterial conjunctivitis was observed from May to September. Staphylococcus aureus was the most common bacteria isolate $65.5 \%$ (72 / 110) followed by Staphylococcus epidermidis $19.1 \%$ (21 / 110). Most of the Staphylococcus aureus isolates were found to be sensitive to moxifloxacin $98.6 \%$ (71 / 72) and gentamicin 95.8\% (69 / 72). 25 $\%$ (18 / 72) of Staphylococcus aureus strains were found to be resistant to cefoxitin and were considered as methicillin-resistant Staphylococcus aureus (MRSA) strains. Maximum numbers of gram-negative strains were sensitive to moxifloxacin $100.0 \%$ (9 / 9) followed by tobramycin $88.9 \%$ (8 / 9). Pseudomonas aeruginosa strains showed maximum sensitivity to moxifloxacin 100.0 (8 / 8) followed by ofloxacin and ciprofloxacin $62.5 \%$ (5 / 8).

\section{CONCLUSIONS}

This study provides an insight into the organisms isolated from cases of bacterial conjunctivitis in Katihar District of Bihar. Determining the susceptibility pattern of these pathogens to available antibiotics is crucial for effective management of bacterial conjunctivitis especially when treatment has to be given empirically.
Corresponding Author:

Dr. Priya Sinha,

Department Microbiology,

Sanjeevni Netralaya,

Near Agarasen Bhawan,

Binodpur, Katihar - 854105,

Bihar, India.

E-mail: drpriyasinha19@gmail.com

DOI: $10.14260 /$ jemds/2021/230

How to Cite This Article:

Sinha P, Dey S, Sen A, et al. Bacteriological profile of organisms isolated from patients with conjunctivitis in Katihar, Bihar. I Evolution Med Dent Sci 2021;10(15):10791082, DOI: 10.14260/jemds/2021/230

Submission 24-11-2020,

Peer Review 14-02-2021,

Acceptance 19-02-2021,

Published 12-04-2021.

Copyright (C) 2021 Priya Sinha et al. This is an open access article distributed under Creative Commons Attribution License [Attribution 4.0 International (CC BY 4.0)]

\section{KEY WORDS}

Bacterial Conjunctivitis, Antibiogram 


\section{BACKGROUND}

Eye is a unique organ that it is impermeable to external organisms. Rapid flow of tears and the blink reflex mechanically washes the ocular surface and prevents accumulation of microorganisms. The most affected parts of the eye, by pathogens, are the conjunctiva, eyelids and cornea. ${ }^{1}$

Conjunctiva is a thin, translucent membrane lining the anterior part of the sclera and inner surface of the eyelids. Inflammation or infection of the conjunctiva is known as conjunctivitis and is characterised by dilatation of the conjunctival blood vessels, resulting in hyperaemia and oedema of the conjunctiva, typically associated with discharge. ${ }^{2}$

Bacterial conjunctivitis has been reported as the commonest type of infectious conjunctivitis after viral infection. It has also been reported as the primary cause of acute conjunctivitis in children amounting to $50 \%$ to $75 \%$ of cases. Infective conjunctivitis is a common condition in infants and school-going children.

Bacterial conjunctivitis is characterised by purulent or mucopurulent discharge. Many patients may present with non-specific symptoms. The type of discharge may not be diagnostic and sometimes there may be no discharge at all.

It has been seen that a good number of culture proven cases of bacterial conjunctivitis (35.0\%) had serous or no discharge at all. Eyelid matting and absence of itching are strong evidence of bacterial conjunctivitis. Diagnosis of bacterial conjunctivitis is based mainly on clinical findings and microbiological examination is not routinely done. Culture and sensitivity are recommended only when treatment fails, and preferably this should be done a few days after stopping antibiotics and other medications. ${ }^{3}$

Conjunctivitis is a common presentation in the primary care settings. It is difficult to accurately capture the true epidemiology of conjunctivitis because of the high numbers of patients who may self-medicate or delay or decline to seek medical care, and can be because of inaccurate diagnosis in the primary medical care setting. Approximately, $70 \%$ of all patients with acute red eye presenting to primary care, are from low social-economic status. ${ }^{4}$

Bacterial conjunctivitis can be treated easily with antibiotics but usually gram-negative bacteria causing bacterial conjunctivitis such as Haemophilus influenzae, moraxella species, Pseudomonas aeruginosa, Neisseria gonorrhoeae and Chlamydia trachomatis can cause severe perforation within 24 - 48 hours of infection. Severe bacterial conjunctivitis can cause blindness due to underlying systemic disease. ${ }^{5}$

Prevalence and aetiology of acute bacterial conjunctivitis vary from place to place, even within the same country, due to geographical, cultural and socioeconomic variations. ${ }^{6}$ Also, there is shifting trend in susceptibility and resistance of the bacteria towards available antibiotics in the last decade. Therefore, periodic studies to monitor the emerging trends in antibiotic susceptibility and resistance are crucial in guiding antibiotic selection.

This study was conducted to isolate and identify organisms causing bacterial conjunctivitis and to determine their in vitro susceptibility or resistance.

\section{METHODS}

Clinically diagnosed cases of conjunctivitis, attending outpatient services of Department of Ophthalmology, Katihar Medical College from December 2018 to May 2020 were included in the study. Selection of patients for the study was done irrespective of age, sex, occupation and socio-economic status. Written consent was taken from each and every patient and ethical clearance was obtained from the institutional ethical committee.

Sterile normal saline moistened swab was rubbed over the lower conjunctival sac from medial to lateral canthus and back again to the medial canthus very carefully without touching the cornea. Two swabs were collected from each patient and transported to laboratory as soon as possible. Out of the two collected swabs, one was used for microscopy. Direct smears were spread on glass slides and stained with Gram stain and examined under oil emersion lens. The other swab was inoculated on blood agar, MacConkey's Agar and chocolate Agar. The medias were incubated at $37^{\circ} \mathrm{C}$ for 24 hours and cultures with no growth were incubated for further 48 hours. Bacteria were then identified on the basis of cultural characteristics, Gram stain morphology and biochemical tests. ${ }^{7}$ Antimicrobial susceptibility test was carried out on each identified bacterium using disc diffusion method on MuellerHinton agar as per Clinical and Laboratory Standards Institute (CLSI) guidelines. ${ }^{8}$ The organisms isolated were then tested for antibiotic sensitivity against amoxicillin, gentamicin, chloramphenicol, erythromycin (only for staphylococcus), cefoxitin (for MRSA screening), azithromycin, ciprofloxacin, ofloxacin, bacitracin, tobramycin, neomycin and moxifloxacin. The zone of inhibition was measured by using a ruler and compared with a table of zone diameter interpretative standards accepted by CLSI.

\section{Statistical Analysis}

Statistical analysis was carried out using online software www.physics.csbsju.edu/cgi-bin/stats/contingency accessed on 20.8.2020, $P$ value $\leq 0.05$ was considered to be significant and P-value $\leq 0.001$ was considered to be highly significant.

\section{RESULTS}

A total of 175 samples were collected from patients reporting to the Ophthalmology OPD with complaints suggestive of conjunctivitis. Out of these samples collected, $62.8 \%$ (110 / $175)$ showed growth, $6.9 \%(12 / 175)$ showed growth of normal flora and $30.3 \%$ (53 / 175) were sterile. Out of these 110 isolates, $84.5 \%$ (93 / 110) were gram positive cocci and $15.5 \%$ (17 / 110) were gram negative bacilli.

Majority of patients in this study belonged to age group 11 - 20 years and male patients outnumbered the female patients. The male to female ratio was 2.7:1, a finding that was found to be statistically highly significant $(\mathrm{P}$-value $=0.000$ ). Maximum number of bacteriologically proven cases of conjunctivitis were seen in the month of June. Highest number of cases were seen from May to September (Figure 1). Maximum number of cases $47.3 \%(52 / 110)$ were from the low-income group followed by middle income group $38.1 \%$ (42 / 110) and high- 
income group $14.6 \%$ (16 / 110). Unilateral eye involvement was seen in $30 \%$ of patients and bilateral involvement was seen in $70 \%$. This finding was found to be statistically significant $(\mathrm{P}$-value $=0.001)$.

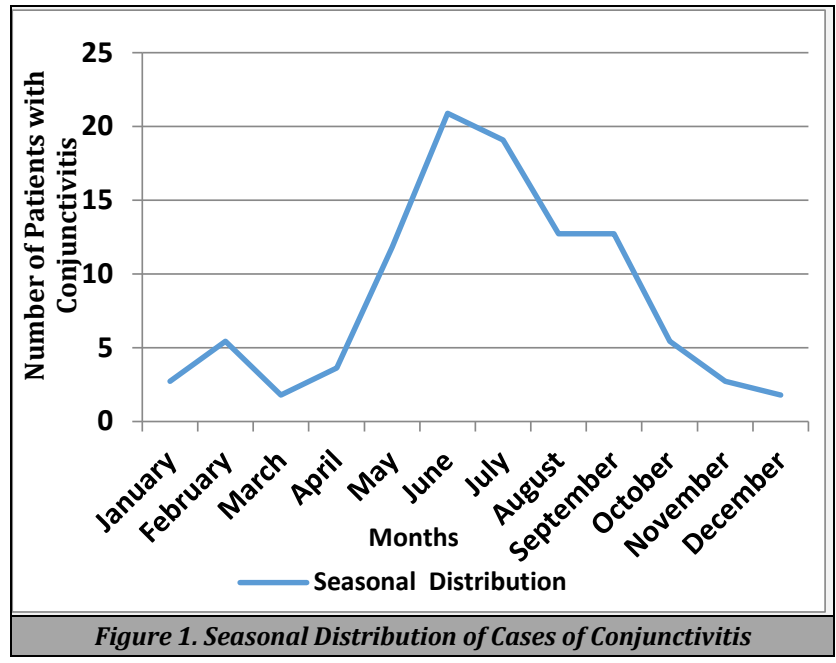

\begin{tabular}{|ccc|}
\hline Isolates & Number & Percentage \\
\hline Gram positive cocci & 93 & 84.5 \\
Gram negative bacilli & 17 & 15.5 \\
\hline Total & 110 & 100.00 \\
\hline Table 1. Gram Positive and Gram Negatives Isolates \\
& in Cases of Bacterial Conjunctivitis \\
\hline
\end{tabular}

\begin{tabular}{|ccc|}
\hline Isolates & Number & Percentage \\
\hline Staphylococcus aureus & 72 & 65.5 \\
Staphylococcus epidermidis & 21 & 19.1 \\
Proteus mirabilis & 1 & 0.9 \\
Haemophilus influenzae & 1 & 0.9 \\
Klebsiella pneumonia & 7 & 6.4 \\
Pseudomonas aeruginosa & 8 & 7.3 \\
Total & 110 & 100.00 \\
\hline Table 2. Bacteria Isolated from Cases of Conjunctivitis \\
\hline
\end{tabular}

\begin{tabular}{|c|c|c|c|}
\hline Antibiotics & $\begin{array}{l}\text { Sensitive } \\
(\%)\end{array}$ & $\begin{array}{c}\text { Intermediate } \\
(\%)\end{array}$ & $\begin{array}{l}\text { Resistant } \\
\text { (\%) }\end{array}$ \\
\hline Amoxicillin & $16(22.2)$ & $30(41.7)$ & $26(36.1)$ \\
\hline Cefoxitin* & $54(75.0)$ & $0(0.0)$ & $18(25.0)$ \\
\hline Gentamicin & $69(95.8)$ & $3(4.2)$ & $0(0.0)$ \\
\hline Ciprofloxacin & $22(30.6)$ & $29(40.3)$ & $21(29.2)$ \\
\hline Azithromycin & $21(29.2)$ & $26(36.1)$ & $25(34.7)$ \\
\hline Erythromycin & 28 (38.9) & $16(22.2)$ & $28(38.9)$ \\
\hline Vancomycin & $62(86.1)$ & $2(2.8)$ & $8(11.1)$ \\
\hline Linezolid & $54(75.0)$ & $4(5.6)$ & $14(19.4)$ \\
\hline Moxifloxacin & $71(98.6)$ & $0(0.0)$ & $1(1.4)$ \\
\hline Chloramphenicol & 64 (88.9) & $5(6.9)$ & $3(4.2)$ \\
\hline Tobramycin & $34(47.2)$ & $21(29.2)$ & 17 (23.6) \\
\hline Bacitracin & $2(2.8)$ & $44(61.1)$ & $26(36.1)$ \\
\hline Neomycin & $6(8.3)$ & $9(12.5)$ & $57(79.2)$ \\
\hline \multicolumn{4}{|c|}{$\begin{array}{l}\text { Table 3. Antimicrobial Susceptibility Pattern of } \\
\text { Staphylococcus aureus }(N=72)\end{array}$} \\
\hline $\mathrm{r}$ detection of $\mathrm{m}$ & lin resista & & \\
\hline
\end{tabular}

Out of the 110 isolates, $93(84.5 \%)$ were gram positive cocci and 17 (15.5\%) were gram negative bacilli (Table 1).

Staphylococcus aureus was the most common bacteria isolated $65.5 \%(72 / 110)$ followed by Staphylococcus epidermidis $19.1 \%$ (21 / 110). Pseudomonas aeruginosa $7.3 \%$ (8 / 110) was the most common gram-negative isolate, followed by Klebsiella pneumoniae $6.4 \%$ (7 / 110). Table 2

Most of the Staphylococcus aureus isolates were found to be sensitive to moxifloxacin $98.6 \%(71 / 72)$ and gentamicin
$95.8 \%$ (69 / 72). $86.1 \%$ (62 / 72) strains were sensitive to vancomycin. Isolates were least sensitive to neomycin $8.3 \%$ (6 / 72) and bacitracin $2.8 \%$ (2 / 72). $25 \%$ (18 / 72) strains were found to be resistant to cefoxitin and were considered as MRSA strains (Table 3).

Maximum numbers of gram-negative strains were sensitive to moxifloxacin $100.0 \%$ ( $9 / 9$ ) followed by tobramycin $88.9 \%$ (8 / 9) (Table 4).

Pseudomonas aeruginosa strains showed maximum sensitivity to moxifloxacin $100.0 \%$ (8 / 8) followed by ofloxacin and ciprofloxacin $62.5 \%$ (5 / 8).

\begin{tabular}{|cccc|}
\hline Antibiotics & $\begin{array}{c}\text { Sensitive } \\
(\%)\end{array}$ & $\begin{array}{c}\text { Intermediate } \\
(\%)\end{array}$ & $\begin{array}{c}\text { Resistant } \\
(\%)\end{array}$ \\
Amoxicillin & $2(22.2)$ & $2(22.2)$ & $5(55.6)$ \\
Gentamicin & $3(33.3)$ & $3(33.3)$ & $3(33.3)$ \\
Ciprofloxacin & $4(44.4)$ & $1(11.1)$ & $4(44.4)$ \\
Azithromycin & $3(33.3)$ & $3(33.3)$ & $3(33.3)$ \\
Ofloxacin & $7(77.8)$ & $0(0.0)$ & $2(22.2)$ \\
Moxifloxacin & $9(100.0)$ & $0(0.0)$ & $0(0.0)$ \\
Chloramphenicol & $3(33.3)$ & $5(55.6)$ & $1(11.1)$ \\
Tobramycin & $8(88.9)$ & $0(0.0)$ & $1(11.1)$ \\
Bacitracin & $0(0.0)$ & $4(44.4)$ & $5(55.6)$ \\
Neomycin & $2(22.2)$ & $2(22.2)$ & $5(55.6)$ \\
\hline \multicolumn{4}{c}{ Table 4. Antimicrobial Susceptibility Pattern of } \\
Gram-Negative Isolates (N = 9) \\
\hline
\end{tabular}

\section{DISCUSSION}

In this study, maximum number of cases were seen in the age group 11 - 20 years, $31.8 \%$ followed by age group 0 - 10 years which comprised of $19.1 \%$ of total number of culture positive cases. Other authors have also reported preponderance of cases in these age groups. ${ }^{2,9,10} \mathrm{~A}$ few authors on the other hand, have reported that the highest rate of bacterial conjunctivitis was found among infants and children in the age group $0-10$ years. ${ }^{11}$

Maximum numbers of patients were males $72.7 \%$. The male to female ratio was 2.7:1 which was found to be statistically highly significant. Similar findings have been reported by various other workers ${ }^{1,9,11}$ However, some authors have reported a greater number of female patients in their study. 10

Overall, highest number of cases were found from May to September $77.3 \%$. Bhattacharyya et al. also reported the same finding in their study which was conducted in Assam ${ }^{6}$. Culture positivity was $62.9 \%$. The number of gram-positive cocci isolated was much more than the number of gram-negative bacilli. Staphylococcus aureus was the most common gram positive isolate $77.4 \%$ followed by Staphylococcus epidermidis $22.5 \%$. Another similar study conducted by Bhattacharyya et al. also reported similar findings with Staphylococcus aureus being the predominant organism $32.1 \%$ followed by Staphylococcus epidermidis $29.1 \%{ }^{6}$

Most of the isolates of Staphylococcus aureus were found to be sensitive to moxifloxacin $98.6 \%$ and gentamicin $95.8 \% .25$ $\%$ of strains were found to be resistant to cefoxitin thereby indicating MRSA strains. A study conducted by Okesola et al. also showed the prevalence rate of methicillin resistant to be $12.0 \%$ in Staphylococcus aureus isolates. ${ }^{12}$ Others have however reported a prevalence rate of $34.7 \%$ of MRSA among Staphylococcus aureus isolates. ${ }^{13} \mathrm{~A}$ few others have found an 
increase in MRSA rates from $4.4 \%$ in 1994 to $42.9 \%$ in 2003 in paediatric patients with bacterial conjunctivitis. ${ }^{14}$ In the present study, Pseudomonas aeruginosa $47.1 \%$ was the most common gram negative isolate, followed by Klebsiella pneumoniae $41.2 \%$. Proteus mirabilis $5.9 \%$ and Haemophilus influenzae $5.9 \%$ were least common gram-negative isolates. Maximum numbers of gram-negative strains were sensitive to moxifloxacin $100.0 \%$ followed by tobramycin $88.9 \%$. Pseudomonas aeruginosa strains showed maximum sensitivity to moxifloxacin 100.0 followed by ofloxacin and ciprofloxacin $62.5 \%$ (5 / 8).

Rajesh et al. also reported that gram negative bacterial isolates were most susceptible to ofloxacin and ciprofloxacin. ${ }^{1}$

\section{CONCLUSIONS}

Eye is a unique organ. It is one of the most important sensory organs in the body. It is a complex and sensitive organ and is vulnerable to trauma and infections. The Indian population is vulnerable to infections of eye by virtue of subtropical climate, trauma and iatrogenic procedures. Even what may be considered a minor infection elsewhere in the body, can be considered fatal to the eye and hence proper diagnosis and treatment of these infections is of utmost importance. In our study, majority of patients were children (11 - 20 years) followed by infants ( 0 - 10 years). Most of the cases occurred from May to September. Majority of cases of conjunctivitis belonged to low socio-economic group. As the hospital, in which this study was conducted, caters to poor patients from surrounding agricultural areas of Bihar and West Bengal, maximum number of cases were seen in the low-income group.

The present study has shown that the prevalence of bacterial infection among patients with conjunctivitis is high $62.8 \%$. The present study has also shown that the most common bacterium responsible for conjunctivitis in this area is Staphylococcus aureus, being responsible for $65.5 \%$ of all cases. This is similar to other studies which have demonstrated the same trends.

Other predominant isolates were Staphylococcus epidermidis, Pseudomonas aeruginosa and Klebsiella pneumoniae. The best available antibiotic for the treatment of bacterial conjunctivitis was moxifloxacin but majority of strains, both gram positive and gram negative, were found to be sensitive to this antibiotic. Most of the isolates were also sensitive to aminoglycosides, chloramphenicol and cephalosporin. Resistance to antibiotics like bacitracin and neomycin was extremely common and these two antibiotics were not used for the treatment of conjunctivitis in our region. Among the Staphylococcus aureus strains, $25.0 \%$ were found to be MRSA. Overall resistance of various organisms to the antibiotics against which they were tested was found to be fairly high. In order to prevent the increasing rate of antimicrobial resistance, avoidance of empirical therapy is advocated. Routine culture and sensitivity of the causative organism must be done especially in the centers where ophthalmologists have access to microbiology laboratories.

Improper selection of antibiotics, inadequate dosing, and poor compliance may play an important a role in emergence of resistant strains of bacteria. Changing patterns of bacterial resistance has been a major hurdle in the effective management of ocular infections. Early access to medical facilities, proper diagnosis, appropriate treatment and better patient health education can prevent the ocular morbidity.

Data sharing statement provided by the authors is available with the full text of this article at jemds.com.

Financial or other competing interests: None.

Disclosure forms provided by the authors are available with the full text of this article at jemds.com.

\section{REFERENCES}

[1] Rajesh S, Divya B, Aruna V. Microbiological profile of external ocular infections in a tertiary care hospital in South India. Int J Curr Microbiol App Sci 2017;6(7):434352.

[2] Veena CN. Bacteriological study of conjunctivitis. International Journal of Contemporary Medical Research 2016;3(10):2829-32.

[3] Hashish AA, Elbakary MA, Allam WA, et al. Resistant infantile bacterial conjunctivitis in Egypt: a microbiological study. J Pediatr Ophthalmol Strabismus 2018;55(2):135-9.

[4] Yeu E, Hauswirth S. A review of the differential diagnosis of acute infectious conjunctivitis: implications for treatment and management. Clin Ophthalmol 2020;14:805-13.

[5] Ahmad S. Diagnosis and management of bacterial conjunctivitis. Acta Scientific Pharmaceutical Sciences 2018;2(11):80-5.

[6] Bhattacharyya A, Sarma P, Sarma B, et al. Bacteriological pattern and their correlation with complication in culture positive cases of acute bacterial conjunctivitis in a tertiary care hospital of upper Assam: a cross sectional study. Medicine (Baltimore) 2020;99(7):e18570.

[7] Collee JG, Miles RS, Watt B, et al. Mackie and McCartney practical medical microbiology. 14th edn. New Delhi: Churchill Livingstone 2006:131-49.

[8] CLSI. Performance standards for antimicrobial susceptibility testing. $30^{\text {th }}$ edn. CLSI supplement M100. M2-A9. Wayne, PA: Clinical and Laboratory Standards Institute 2020.

[9] Shrestha SP, Khadka J, Pokhrel AK, et al. Acute bacterial conjunctivitis-antibiotic susceptibility and resistance to commercially available topical antibiotics in Nepal. Nepal J Ophthalmol 2015;8(15):23-5.

[10] Ahmed OB, Hamdan EM. Profile of bacterial conjunctivitis in Sudan. Sch J App Med Sci 2016;4(4B):1217-21.

[11] Okesola AO, Salako AO. Microbiological profile of bacterial conjunctivitis in Ibadan, Nigeria. Ann Ib Postgrad Med 2010;8(1):20-4.

[12] Okesola OO, Oni AA, Bakare RA. Prevalence and antibiotic sensitivity pattern of methicillin-resistant Staphylococcus aureus in Ibadan, Nigeria. J Hosp Inf 1999;41(1):74-5.

[13] Taiwo SS, Onile BA, Akanbi AA. Methicillin Resistant Staphylococcus aureus (MRSA) isolates in Ilorin, Nigeria. Afr J Clin Exp Microbiol 2004;5(2):189-97.

[14] Cavuoto K, Zutshi D, Karp CL, et al. Update on bacterial conjunctivitis in South Florida. Ophthalmology 2008;115(1):51-6. 